\title{
The German ECMO inflation: when things other than health and care begin to rule medicine
}

\author{
M. Quintel ${ }^{1 *}$, L. Gattinoni ${ }^{1}$ and S. Weber-Carstens ${ }^{2}$
}

๑ 2016 Springer-Verlag Berlin Heidelberg and ESICM

In an article recently published in Intensive Care Medicine, Karagiannidis et al. analyze data from the Federal Statistical Office of Germany (Statistisches Bundesamt, Wiesbaden, Germany) on the use of extracorporeal membrane oxygenation (ECMO) in venovenous (vv) and venoarterial (va) mode in Germany [1] regarding the demographic of the treated population, the incidence and mode of ECMO use, and the outcomes for the period between 1 January 2007 and 31 December 2014. This editorial focuses on aspects of ECMO in the vv mode.

Historically, ECMO was used an adjunct to mechanical ventilation whenever blood gas tensions deviated significantly from physiological normal limits despite extreme ventilator settings. The external "artificial lung" was only an "add on" and did not reduce the deleterious power transmitted to the lungs with each tidal volume. The extracorporeal lung's potential to allow less harmful ventilator settings was first described by Gattinoni and co-workers [2]. It is interesting that, to begin with, ventilatory strain was mainly reduced by lowering the respiratory frequency, and not so much by reducing the power transmitted during each inflation.

In the two decades following the negative results of two randomized controlled trials [3, 4], a small number of centers continued to use ECMO when they were convinced that mechanical ventilation alone would not be sufficient to prevent the death of the patient.

ECMO existed peacefully in this niche-in some centers even very successfully with quite large numbers of

\footnotetext{
*Correspondence: mquintel@med.uni-goettingen.de

${ }^{1}$ Department of Anesthesiology, Emergency and Intensive Care Medicine Universitätsmedizin Göttingen, Robert Koch Strasse 40, 37073 Göttingen, Germany

Full author information is available at the end of the article
}

treated patients [5] - while knowledge of the injurious effects of mechanical ventilation steadily accumulated. This finally led to a large randomized controlled trial that provided the first clear evidence that aggressive mechanical ventilation was costing lives [6]. The underlying ventilator-induced lung injury (VILI) and efforts to reduce it became the focus of research and clinical practice. The 2007-2008 and 2008-2009 H1N1 influenza outbreaks catalyzed not only the renaissance of ECMO but also triggered a veritable hype that set off a worldwide explosion in its use [1,7-9]. The exaggerated expectations may have been additionally stimulated by the encouraging results of a randomized controlled trial [10].

H1N1 created a formidable number of "cannot ventilate" patients. Consolidation of the entire lung made it impossible to apply any reasonable tidal volume. In this scenario, ECMO again became attractive for obvious reasons.

The renaissance of ECMO encountered an environment in which the prevention of VILI had become the holy grail of mechanical ventilation. Extracorporeal lung assist was recognized as a potentially powerful tool in this endeavor $[11,12]$. As a consequence, "ECMO" in vv and av mode was applied with increasing frequency using flow ranges between 400 and $6000 \mathrm{ml} / \mathrm{min}$ to reduce VILI and/or to ensure adequate gas exchange. The enthusiasm was additionally driven by the belief that ECMO had become safer. While this might be true for the equipment, i.e., oxygenators, priming volumes, pumps, cannulas, etc., the inherent risks of ECMO with its exposure to a large, non-endothelial surface, large-bore cannulas in central vessels, and most importantly the need for anticoagulation in a fine balance between bleeding and thrombosis had considerable potential for serious

\section{实 Springer}


complications-cerebral hemorrhage during ECMO is still a reality. Ignoring this fact led to the data presented in the publication by Karagiannidis and colleagues.

Karagiannidis and colleagues found that vv-ECMO use increased from 1.0:100,000 inhabitants/year in 2007 to $3.0: 100,000$ in 2012 with a decrease to $2.4: 100,000$ in 2014 . Mortality decreased slightly during this period and leveled off at ca. $60 \%$. The proportion of older patients receiving ECMO had increased steadily and included many patients older than 80 years even though mortality increases with age. Mortality was particularly high during the first $48 \mathrm{~h}$ after starting ECMO. A major finding was that the patients who had received ECMO for less than $48 \mathrm{~h}(25 \%)$ had a mortality rate of $70 \%$. The simple but alarming truth behind these numbers is that ECMO was either not indicated in these patients or that they died of procedure-related complications.

Recent data from the USA show a similar trend with a fivefold increase of vv-ECMO use between 2006 and 2011 , and mortality rates of roughly $60 \%$ [8]. The patients receiving ECMO in the USA were markedly younger than those in the study by Karagiannidis and colleagues.

The worldwide frequency and intensity of vv-ECMO use are definitely "outside the box", the box being the rules that should govern the use of therapy options. We need more than proof of principle before a treatment is widely disseminated. We need exact information on its complication rates, and we need stronger evidence than currently available that its use improves survival compared to conventional treatment.

The mortality of ECMO patients reported in the studies by Karagiannidis and Rush is higher than in epidemiological studies on ARDS, and this also remains true for patients with severe ARDS $[13,14]$. Conflicting data even exist for patients with the "ECMO trigger disease" H1N1. Two studies, one with ECMO as treatment option and the other without, had similar survival rates $[15,16]$.

The enormous increase in the use of ECMO despite the fact that clear evidence of its superiority for any currently used indication is lacking might have been promoted by national regulations and reimbursement policies. Across Europe the rules under which ECMO is performed vary widely. This is true for regulations dealing with a number of "ECMO centers" (restricted in the UK and Italy, not so in France and Germany). Sweden, which has no restrictions, has only one center except during pandemics, while in France and Germany the number of so-called ECMO centers and ECMO providers is out of control. The same diversity also exists for reimbursement, which ranges from no reimbursement (Switzerland, Sweden) to partial reimbursement (UK) or special extrabudgetary compensation (Germany). Financial interests, fascination with new gadgets, and ambition might be driving the development more than we imagine.

The three authors, although having used ECMO for roughly three decades, are now in the paradoxical situation of being strong advocates for a thorough evaluation of its indications, and a careful determination of its side effects at different levels of extracorporeal support, while realizing that we have is more belief than true knowledge.

To retain the opportunity of further developing and applying extracorporeal lung support techniques for our patients' benefit, we must critically reflect on what we actually do. The work of Karagiannidis and colleagues strongly supports this approach. It is much better that physicians define the rules on how and when to apply ECMO properly, instead of waiting until negative risk/ benefit ratios, fatal outcomes, and stake holders with vested interests ban ECMO.

\section{Author details}

${ }^{1}$ Department of Anesthesiology, Emergency and Intensive Care Medicine Universitätsmedizin Göttingen, Robert Koch Strasse 40, 37073 Göttingen, Germany. ${ }^{2}$ Department of Anesthesiology and Operative Intensive Care Medicine, Campus Virchow \& Campus Mitte, Charité-Universitätsmedizin Berlin, Augustenburger-Platz 1, 13353 Berlin, Germany.

Received: 7 April 2016 Accepted: 5 May 2016

Published online: 6 June 2016

\section{References}

1. Karagiannidis C, Brodie D, Strassmann S, Stoelben E, Philipp A, Bein T, Müller T, Windisch W (2016) Extracorporeal membrane oxygenation: evolving epidemiology and mortality. Intensive Care Med 42:889-896. doi:10.1007/s00134-016-4273-z

2. Gattinoni L, Kolobow T, Agostoni A, Damia G, Pelizzola A, Rossi GP, Langer M, Solca M, Citterio R, Pesenti A, Fox U, Uziel L (1979) Clinical application of low frequency positive pressure ventilation with extracorporeal $\mathrm{CO}_{2}$ removal (LFPPV-ECCO $2 \mathrm{R}$ ) in treatment of adult respiratory distress syndrome (ARDS). Int J Artif Organs 2:282-283

3. Zapol WM, Snider MT, Hill JD, Fallat RJ, Bartlett RH, Edmunds LH, Morris AH, Peirce EC 2nd, Thomas AN, Proctor HJ, Drinker PA, Pratt PC, Bagniewski A, Miller RG Jr (1979) Extracorporeal membrane oxygenation in severe acute respiratory failure. A randomized prospective study. JAMA 242:2193-2196

4. Morris AH, Wallace $C$, Menlove RL, Clemmer TP, Orme JF Jr, Weaver LK Dean NC, Thomas F, East TD, Pace NL, Suchyta MR, Beck E, Bombino M, Sittig DF, Böhm S, Hoffmann B, Becks H, Butler S, Pearl J, Rasmusson B (1994) Randomized clinical trial of pressure-controlled inverse ratio ventilation and extracorporeal $\mathrm{CO} 2$ removal for adult respiratory distress syndrome. Am J Respir Crit Care Med 149:295-305

5. Bartlett RH, Roloff DW, Custer JR, Younger JG, Hirschl RB (2000) Extracorporeal life support: the University of Michigan experience. JAMA 283:904-908

6. The Acute Respiratory Distress Syndrome Network (2000) Ventilation with lower tidal volumes as compared with traditional tidal volumes for acute lung injury and the acute respiratory distress syndrome. N Engl J Med 342:1301-1308

7. Hsu CP, Lee WC, Wei HM, Sung SH, Huang CY, Shih CC, Lu TM (2015) Extracorporeal membrane oxygenation use, expenditure, and outcomes in Taiwan from 2000 to 2010. J Epidemiol 25:321-331

8. Rush B, Wiskar K, Berger L, Griesdale D (2016) Trends in extracorporeal membrane oxygenation for the treatment of acute 
respiratory distress syndrome in the United States. J Intensive Care Med. doi:10.1177/0885066616631956

9. Belongia EA, Irving SA, Waring SC, Coleman LA, Meece JK, Vandermause M, Lindstrom S, Kempf D, Shay DK (2010) Clinical characteristics and 30-day outcomes for influenza A 2009 (H1N1), 2008-2009 (H1N1), and 2007-2008 (H3N2) infections. JAMA 304:1091-1098

10. Peek GJ, Mugford M, Tiruvoipati R, Wilson A, Allen E, Thalanany MM, Hibbert CL, Truesdale A, Clemens F, Cooper N, Firmin RK, Elbourne D, CESAR trial collaboration (2009) Efficacy and economic assessment of conventional ventilatory support versus extracorporeal membrane oxygenation for severe adult respiratory failure (CESAR): a multicentre randomised controlled trial. Lancet 374:1351-1363

11. Bein T, Weber-Carstens S, Goldmann A, Müller T, Staudinger T, Brederlau J, Muellenbach R, Dembinski R, Graf BM, Wewalka M, Philipp A, Wernecke KD, Lubnow M, Slutsky AS (2013) Lower tidal volume strategy ( $\approx 3 \mathrm{ml} / \mathrm{kg})$ combined with extracorporeal $\mathrm{CO}_{2}$ removal versus 'conventional' protective ventilation $(6 \mathrm{ml} / \mathrm{kg})$ in severe ARDS: the prospective randomized Xtravent-study. Intensive Care Med 39:847-855

12. Perner A, Citerio G, Bakker J et al (2015) Year in review in Intensive Care Medicine 2014: II. ARDS, airway management, ventilation, adjuvants in sepsis, hepatic failure, symptoms assessment and management, palliative care and support for families, prognostication, organ donation, outcome, organisation and research methodology. Intensive Care Med 41:389-401
13. Villar J, Blanco J, Añón JM, Santos-Bouza A, Blanch L, Ambrós A, Gandía F, Carriedo D, Mosteiro F, Basaldúa S, Fernández RL, Kacmarek RM, ALIEN Network (2011) The ALIEN study: incidence and outcome of acute respiratory distress syndrome in the era of lung protective ventilation. Intensive Care Med 37:1932-1941

14. Bellani G, Laffey JG, Pham T, Fan E, Brochard L, Esteban A, Gattinoni L, van Haren F, Larsson A, McAuley DF, Ranieri M, Rubenfeld G, Thompson BT, Wrigge H, Slutsky AS, Pesenti A, LUNG SAFE Investigators, ESICM Trials Group (2016) Epidemiology, patterns of care, and mortality for patients with acute respiratory distress syndrome in intensive care units in 50 Countries. JAMA 315:788-800

15. Australia and New Zealand Extracorporeal Membrane Oxygenation (ANZ ECMO) Influenza Investigators, Davies A, Jones D, Bailey M, Beca J, Bellomo R, Blackwell N, Forrest P, Gattas D, Granger E, Herkes R, Jackson A, McGuinness S, Nair P, Pellegrino V, Pettilä V, Plunkett B, Pye R, Torzillo P, Webb S, Wilson M, Ziegenfuss M (2009) Extracorporeal membrane oxygenation for 2009 influenza A (H1N1) acute respiratory distress syndrome. JAMA 302(17):1888-1895

16. Miller RR 3rd, Markewitz BA, Rolfs RT, Brown SM, Dascomb KK, Grissom CK, Friedrichs MD, Mayer J, Hirshberg EL, Conklin J, Paine R 3rd, Dean NC (2010) Clinical findings and demographic factors associated with ICU admission in Utah due to novel 2009 influenza A (H1N1) infection. Chest 137:752-758 